Rev. High Pressure Sci. Technol., Vol. 7 (1998) 1016 1018

\title{
High Pressure Synthesis and Structures of Scandium-Zinc Intermetallic Compounds $\mathrm{ScZn}_{2}, \mathrm{Sc}_{3} \mathrm{Zn}_{17}$ and $\mathrm{Sc}_{13} \mathrm{Zn}_{58}$
}

\author{
Xiaoyang Liu, Regina Ehrl and Klaus-Jürgen Range \\ Institute of Inorganic Chemistry, Regensburg University \\ Universitystreet 31, D-93053 Regensburg, Germany
}

\begin{abstract}
Three kinds of scandium-zinc intermetallic compounds, $\mathrm{ScZn}_{2}, \mathrm{Sc}_{3} \mathrm{Zn}_{17}$ and $\mathrm{Sc}_{13} \mathrm{Zn}_{58}$ have been prepared from the elements under high pressure and high temperature. $\mathrm{ScZn}_{2}$ crystallizes in the hexagonal system with lattice constants $a=5.2509 \AA, c=8.4774 \AA, c / a=1.6147$, and unit cell valume $202.42 \AA^{3} . \mathrm{Sc}_{3} \mathrm{Zn}_{17}$ crystallizes in the cubic system with lattice constant $a=13.8406 \AA$ and unit cell volume $2661.35 \AA^{3} . \mathrm{Sc}_{13} \mathrm{Zn}_{58}$ crystallizes in the hexagonal system with lattice constant $a=13.744 \AA, c=13.632 \AA, c / a=0.9919$, and unit cell volume $2230.06 \AA^{3}$. The usefulness of high pressure methods for the synthesis of intermetallic phases with highly volatile components could again be demonstrated here.

[high pressure synthesis, scandium-zinc intremetallic compounds, alloy, X-ray diffraction]
\end{abstract}

\section{Introduction}

In recent years a number of reports on the alloying behaviour of the rare earths with zinc have been published. Full structure data on the $\mathrm{MZn}$ and $\mathrm{MZn}_{2}$ compounds are available. For $\mathrm{Zn}$ rich alloy, crystal structures have been found corresponding to the formulae $\mathrm{M}_{2} \mathrm{Zn}_{17}, \mathrm{MZn}_{11}, \mathrm{MZn}_{12}$, and $\mathrm{MZn}_{13}$. The alloy phase diagrams of $\mathrm{Zn}$ with $\mathrm{Y}, \mathrm{La}, \mathrm{Ce}, \mathrm{Pr}, \mathrm{Nd}, \mathrm{Sm}$, and $\mathrm{Yb}$ are known and are generally characterized by a large number of intermetallic phases[1], but no phase diagram is available for the $\mathrm{Sc}-\mathrm{Zn}$ system. Recently we have succeeded in the preparation of a new compound with 1:2 stoichiometry, $\mathrm{ScZn}_{2}$, hitherto unknown in the Sc-Zn system [2]. In the present paper, we report the latest developments in Sc-Zn system, which are about the high pressure synthesis and structures of scandiumzinc intermetallic compounds $\mathrm{ScZn}_{2}, \mathrm{Sc}_{3} \mathrm{Zn}_{17}$ and $\mathrm{Sc}_{13} \mathrm{Zn}_{58}$.

\section{Experimental details}

High pressure experiments were carried out in a modified Belt-type apparatus using crucibles made of h-BN for the synthesis of scandium-zinc intermetallic compounds, and starting with stoichiometric mixtures of scandium $(99.999 \%$; Alfa) and zinc (99.999\%; Alfa) for $\mathrm{ScZn}_{2}, \mathrm{Sc}_{3} \mathrm{Zn}_{17}$, and $\mathrm{Sc}_{13} \mathrm{Zn}_{58}$, respectively. The crystals of $\mathrm{ScZn}_{2}, \mathrm{Sc}_{3} \mathrm{Zn}_{17}$, and $\mathrm{Sc}_{13} \mathrm{Zn}_{58}$ were found after the following treatment:

$\mathrm{ScZn}{ }_{2}$ Heating to $1900^{\circ} \mathrm{C}$ at $3.5 \mathrm{GPa}$ (heating rate $190^{\circ} \mathrm{C} / \mathrm{min}$ ), keeping the temperature at $1900^{\circ} \mathrm{C}$ for $20 \mathrm{~min}$, cooling down (cooling rate $35^{\circ} \mathrm{C} / \mathrm{min}$ ) to $1200^{\circ} \mathrm{C}$. The samples were annealed at this value for another $60 \mathrm{~min}$. After cooling down to the room temperature (cooling rate $25^{\circ} \mathrm{C} / \mathrm{min}$ ), the pressure was released.

$\mathrm{Sc}_{3} \mathrm{Zn}_{17}$ Heating to $1900^{\circ} \mathrm{C}$ at $3.5 \mathrm{GPa}$ (heating rate $190^{\circ} \mathrm{C} / \mathrm{min}$ ), keeping the temperature at $1900^{\circ} \mathrm{C}$ for $30 \mathrm{~min}$, cooling down (cooling rate $10^{\circ} \mathrm{C} / \mathrm{min}$ ) to $1600^{\circ} \mathrm{C}$, keeping the temperature at this value for another $100 \mathrm{~min}$. The sample was quenched to the room temperature before the pressure was released.

$S c_{13} Z n_{58}$ Heating the starting materials to $1900^{\circ} \mathrm{C}$ at $4.0 \mathrm{GPa}$ (heating rate $190^{\circ} \mathrm{C} / \mathrm{min}$ ), keeping the temperature at $1900^{\circ} \mathrm{C}$ for $100 \mathrm{~min}$, cooling down (cooling rate $8^{\circ} \mathrm{C} / \mathrm{min}$ ) to $1200^{\circ} \mathrm{C}$. The samples were annealed at this value for another $150 \mathrm{~min}$. After cooling down to the room temperature (cooling rate $12^{\circ} \mathrm{C} / \mathrm{min}$ ), the pressure was released.
The brittle reaction products which were in a grey matrix were not very sensitive to moist air.

After high pressure and high temperature experiments, crystal fragments suitable for a single crystal X-ray study could be selected from the reaction products. The crystals were checked by oscillation and Weissenberg photograph and subseguently used for data collection on an Enraf-Nonius CAD-4 diffractometer or STOE imaging plate diffraction system.

$\mathrm{X}$-ray powder diffraction studies were performed using STOE X-ray powder diffraction system.

EDX measurement (Zeiss DSM 950) confirmed the existence of scandium zinc intermetallic compounds $\mathrm{ScZn}_{2}, \mathrm{Sc}_{3} \mathrm{Zn}_{17}$, and $\mathrm{Sc}_{13} \mathrm{Zn}_{58}$.

\section{Discussion}

The basic crystal data for scandium-zinc iniermetallic compounds $\mathrm{ScZn}_{2}, \mathrm{Sc}_{3} \mathrm{Zn}_{17}$, and $\mathrm{Sc}_{13} \mathrm{Zn}_{58}$ are listed in Table 1 . $\mathrm{X}$-ray powder diffraction data of scandium zinc intermetallic compounds $\mathrm{ScZn}_{2}, \mathrm{Sc}_{3} \mathrm{Zn}_{17}$, and $\mathrm{Sc}_{13} \mathrm{Zn}_{58}$ are listed in Table 2,

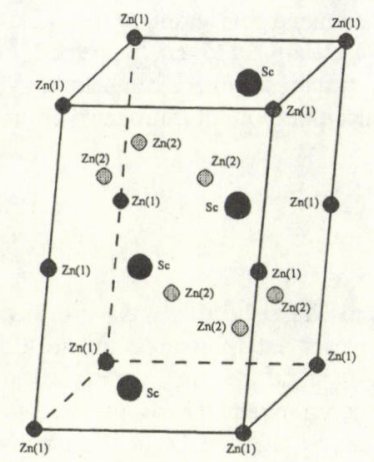

Fig.1. Unit cell structure of scandium-zinc intermetallic compound $\mathrm{ScZn}_{2}$

Table 3 and Table 4, respectively, which are average value derived from a least squares fitting of X-ray powder diffraction data. 
Table 1 Crystal Data for scandium-zinc iniermetallic compounds $\mathrm{ScZn}_{2}, \mathrm{Sc}_{3} \mathrm{Zn}_{17}$, and $\mathrm{Sc}_{13} \mathrm{Zn}_{58}$

\begin{tabular}{cccccc}
\hline Compounds & Crystal System & Cell Constans $(\AA)$ & Cell Volume $\left(\AA^{3}\right)$ & Structural Types & Space Groop \\
\hline $\mathrm{ScZn}_{2}$ & Hexagonal & $a=5.2509(8)$ & 202.42 & $\mathrm{MgZn}_{2}$ & $P 6_{3} / m m c$ \\
& & $c=8.4774(14)$ & & & $($ No. 194) \\
& & $c / a=1.6147$ & & \\
$\mathrm{Sc}_{3} \mathrm{Zn}_{17}$ & Cubic & $a=13.8406(6)$ & 2661.35 & $\mathrm{Ru}_{3} \mathrm{Be}_{17}$ & $I m \overline{3}(N o .204)$ \\
$\mathrm{Sc}_{13} \mathrm{Zn}_{58}$ & Hexagonal & $a=13.744(1)$ & 2230.06 & $\mathrm{Gd}_{13} \mathrm{Zn}_{58}$ & $P 6_{3} m c$ \\
& & $c=13.632(1)$ & & $(N o .186)$ \\
& & $c / a=0.9919$ & & \\
& & & & \\
\end{tabular}

Table 2. X-ray Powder Diffraction Data of Scandium Zinc Intermetallic Compounds $\mathrm{ScZn}$

\begin{tabular}{|c|c|c|c|c|}
\hline $2 \theta$ & $\mathrm{I} / \mathrm{I}_{0}$ & h k l & $\mathrm{d}_{\mathrm{obs}}(\AA)$ & $\mathrm{d}_{\mathrm{calc}}(\AA)$ \\
\hline 10.439 & 9.4 & $\begin{array}{lll}0 & 0 & 1\end{array}$ & 8.4673 & 8.4672 \\
\hline 19.495 & 22.6 & 100 & 4.5495 & 4.5470 \\
\hline 20.940 & 18.0 & 002 & 4.2389 & 4.2381 \\
\hline 22.162 & 16.7 & $\begin{array}{lll}10 & 0\end{array}$ & 4.0078 & 4.0068 \\
\hline 34.119 & 21.4 & 110 & 2.6257 & 2.6252 \\
\hline 37.445 & 52.0 & 103 & 2.3997 & 2.3998 \\
\hline 39.611 & 19.2 & 200 & 2.2733 & 2.2735 \\
\hline 40378 & 100.0 & 112 & 2.2319 & 2.2317 \\
\hline 41.060 & 86.3 & 201 & 2.1964 & 2.1959 \\
\hline 42.642 & 26.9 & $\begin{array}{lll}0 & 0 & 4\end{array}$ & 2.1185 & 2.1190 \\
\hline 45.228 & 28.7 & 202 & 2.0032 & 2.0034 \\
\hline 47.291 & 16.5 & 104 & 1.9205 & 1.9207 \\
\hline 51.555 & 11.7 & 203 & 1.7713 & 1.7713 \\
\hline 53.280 & 5.5 & 210 & 1.7179 & 1.7186 \\
\hline 63.295 & 17.8 & 213 & 1.4681 & 1.4683 \\
\hline 65.328 & 16.9 & 302 & 1.4272 & 1.4271 \\
\hline 66.064 & 6.1 & 006 & 1.4131 & 1.4127 \\
\hline 69.073 & 22.0 & 205 & 1.3587 & 1.3590 \\
\hline 70.497 & 9.2 & 214 & 1.3347 & 1.3348 \\
\hline 71.859 & 20.9 & 220 & 1.3127 & 1.3126 \\
\hline 83.960 & 7.8 & $\begin{array}{lll}3 & 13\end{array}$ & 1.1516 & 1.1516 \\
\hline 86.247 & 9.4 & 401 & 1.1268 & 1.1267 \\
\hline 87.308 & 15.9 & 224 & 1.1159 & 1.1159 \\
\hline 90.613 & 5.2 & $\begin{array}{lll}3 & 1 & 4 \\
\end{array}$ & 1.0836 & 1.0837 \\
\hline
\end{tabular}

$\mathrm{ScZn}_{2}$ From the X-ray diffractometer data a hexagonal unit cell with lattice constant $a=5.2509(8) \AA, c=8.4774(14) \AA$, $c / a=1.6147$ and unit cell volume $202.42 \AA^{3}$ was found. The observed reflection conditions $(l=2 n$ for $h h-2 h l)$ pointed to the possible space group $\mathrm{PG}_{3} \mathrm{mc}$ and $\mathrm{PG}_{3} / \mathrm{mmc}$. From statistical analysis of the normalized structure amplitudes an inversion centre was found, arriving at the centric space group $\mathrm{PG}_{3} / \mathrm{mmc}$. The result of the structure refinement confirmed this space group choice[2]. The unit cell structure of scandium-zinc intermetallic compound $\mathrm{ScZn}_{2}$ is shown in figure 1. It crystallizes with a $\mathrm{Cl} 4\left(\mathrm{MgZn}_{2}\right)$ type structure.

$\mathrm{Sc}_{3} Z n_{l}:$ : A cubic unit cell with lattice constant $a=13.8406(6)$ $\AA$ and unit cell volume $2661.35 \AA^{3}$ was found from the X-ray diffractometer data. The observed reflection conditions $(h+k+l=2 n$ for $h k l)$ pointed to the space group $I m \overline{3}$.

$S c_{13} Z_{n}$ : From the X-ray diffractometer data a hexagonal unit cell with lattice constants $a=13.744 \AA, c=13.632 \AA, c / a=0.9919$, and unit cell volume $2230.06 \AA^{3}$ was found. The observed reflection conditions ( $l=2 n$ for $h h-2 h l$ ) pointed to the space group $\mathrm{Pb}_{3} \mathrm{mc}$

During the preparation of zinc-rich alloys, problems often arise due to the relative high volatility of zinc. Consequently,

Table 3. X-ray Powder Diffraction Data of Intermetallic Compounds $\mathrm{Sc}_{3} \mathrm{Zn}_{17}$

\begin{tabular}{|c|c|c|c|c|}
\hline $2 \theta$ & $\mathrm{I} / \mathrm{I}_{0}$ & h k 1 & $\mathrm{~d}_{\mathrm{obs}}(\AA)$ & $\mathrm{d}_{\mathrm{calc}}(\AA)$ \\
\hline 9.014 & 2.2 & $\begin{array}{lll}110 & 10\end{array}$ & 9.8023 & 9.7867 \\
\hline 12.784 & 5.4 & 200 & 6.9186 & 6.9191 \\
\hline 20.272 & 6.9 & $\begin{array}{lll}3 & 1 & 0\end{array}$ & 4.3769 & 4.3768 \\
\hline 24.037 & 5.0 & 321 & 3.6991 & 3.6992 \\
\hline 27.300 & 4.2 & 330 & 3.2640 & 3.2623 \\
\hline 28.821 & 13.5 & 420 & 3.0951 & 3.0949 \\
\hline 31.642 & 4.8 & 422 & 2.8254 & 2.8253 \\
\hline 32.992 & 4.1 & 431 & 2.7127 & 2.7144 \\
\hline 35.488 & 6.8 & 521 & 2.5275 & 2.5270 \\
\hline 37.870 & 73.2 & 433 & 2.3738 & 2.3737 \\
\hline 39.008 & 29.3 & 442 & 2.3071 & 2.3068 \\
\hline 40.129 & 100.0 & 532 & 2.2452 & 2.2453 \\
\hline 41.214 & 9.6 & 620 & 2.1886 & 2.1884 \\
\hline 42.278 & 5.3 & 541 & 2.1359 & 2.1357 \\
\hline 44.351 & 39.7 & $\begin{array}{lll}6 & 31\end{array}$ & 2.0408 & 2.0407 \\
\hline 46.348 & 28.5 & 543 & 1.9574 & 1.9574 \\
\hline 47.321 & 20.6 & 640 & 1.9194 & 1.9194 \\
\hline 48.280 & 5.2 & 552 & 1.8835 & 1.8835 \\
\hline 49.221 & 8.6 & 642 & 1.8496 & 1.8496 \\
\hline 57.209 & 3.5 & 743 & 1.6089 & 1.6090 \\
\hline 65.311 & 4.8 & 763 & 1.4275 & 1.4276 \\
\hline 66.089 & 3.6 & 844 & 1.4126 & 1.4126 \\
\hline 66.868 & 14.3 & 770 & 1.3980 & 1.3981 \\
\hline 67.636 & 4.1 & 860 & 1.3840 & 1.3841 \\
\hline 69.912 & 2.9 & 943 & 1.3444 & 1.3444 \\
\hline 70.669 & 2.9 & 666 & 1.3319 & 1.3318 \\
\hline 71.420 & 19.2 & 765 & 1.3197 & 1.3197 \\
\hline 72.921 & 5.5 & 774 & 1.2962 & 1.2963 \\
\hline 73.645 & 2.8 & 864 & 1.2852 & 1.2851 \\
\hline 74.395 & 6.5 & 961 & 1.2741 & 1.2742 \\
\hline 75.872 & 2.7 & 873 & 1.2529 & 1.2531 \\
\hline 84.505 & 3.7 & 974 & 1.1456 & 1.1455 \\
\hline 86.644 & 6.5 & 1064 & 1.1227 & 1.1226 \\
\hline 87.357 & 2.7 & 983 & 1.1154 & 1.1153 \\
\hline 88.785 & 2.4 & 1073 & 1.1011 & 1.1011 \\
\hline 90.197 & 4.8 & 877 & 1.0875 & 1.0874 \\
\hline 90.914 & 2.6 & 886 & 1.0808 & 1.0808 \\
\hline 91.623 & 2.4 & 976 & 1.0742 & 1.0742 \\
\hline 93.049 & 2.4 & 985 & 1.0615 & 1.0615 \\
\hline 94.464 & 1.9 & 1075 & 1.0493 & 1.0492 \\
\hline
\end{tabular}


Table 4. X-ray Powder Diffraction Data of Intermetallic Compounds $\mathrm{Sc}_{13} \mathrm{Zn}_{58}$

\begin{tabular}{|c|c|c|c|c|c|}
\hline $2 \theta$ & $\mathrm{I} / \mathrm{I}_{0}$ & h k & & $\mathrm{d}_{\text {obs }}(\AA)$ & $\mathrm{d}_{\mathrm{calc}}(\AA)$ \\
\hline 7.426 & 4.4 & 100 & & 11.8945 & 11.8985 \\
\hline 9.849 & 2.3 & 101 & 1 & 8.9731 & 8.9638 \\
\hline 12.880 & 2.3 & 110 & 0 & 6.8674 & 6.8696 \\
\hline 18.310 & 2.2 & 112 & & 4.8412 & 4.8383 \\
\hline 19.489 & 2.6 & $\begin{array}{lll}0 & 0 & 3\end{array}$ & 3 & 4.5511 & 4.5436 \\
\hline 20.925 & 4.1 & 103 & & 4.2417 & 4.2447 \\
\hline 23.336 & 6.6 & $\begin{array}{lll}3 & 0 & 1\end{array}$ & 1 & 3.8088 & 3.8082 \\
\hline 23.686 & 4.1 & 212 & 2 & 3.7532 & 3.7537 \\
\hline 24.634 & 3.5 & 203 & 3 & 3.6109 & 3.6110 \\
\hline 25.919 & 4.6 & 220 & 0 & 3.4348 & 3.4348 \\
\hline 27.194 & 2.3 & 104 & 4 & 3.2765 & 3.2760 \\
\hline 27.884 & 2.1 & 213 & 3 & 3.1969 & 3.1963 \\
\hline 29.244 & 2.9 & 114 & 4 & 3.0513 & 3.0528 \\
\hline 30.213 & 2.7 & 204 & 4 & 2.9556 & 2.9570 \\
\hline 30.749 & 2.0 & 401 & 1 & 2.9053 & 2.9062 \\
\hline 35.160 & 3.1 & 411 & 1 & 2.5503 & 2.5506 \\
\hline 36.055 & 4.5 & 403 & 3 & 2.4890 & 2.4887 \\
\hline 37.138 & 3.1 & 224 & 4 & 2.4189 & 2.4191 \\
\hline 37.771 & 6.6 & 500 & 0 & 2.3798 & 2.3797 \\
\hline 38.440 & 50.5 & 323 & 3 & 2.3399 & 2.3399 \\
\hline 39.318 & 40.0 & 330 & 0 & 2.2896 & 2.2899 \\
\hline 39.634 & 5.8 & 006 & 6 & 2.2721 & 2.2718 \\
\hline 40.106 & 100.0 & 502 & 2 & 2.2464 & 2.2467 \\
\hline 40.371 & 14.1 & 106 & 6 & 2.2323 & 2.2315 \\
\hline 41.854 & 2.3 & 116 & 6 & 2.1566 & 2.1569 \\
\hline 42.270 & 4.9 & 510 & 0 & 2.1363 & 2.1370 \\
\hline 42.853 & 7.1 & 503 & 3 & 2.1086 & 2.1081 \\
\hline 43.801 & 2.6 & 414 & 4 & 2.0651 & 2.0653 \\
\hline 44.393 & 4.3 & 512 & 2 & 2.0390 & 2.0391 \\
\hline 44.947 & 5.2 & 423 & 3 & 2.0151 & 2.0153 \\
\hline 46.009 & 17.6 & 306 & 6 & 1.9710 & 1.9713 \\
\hline 46.228 & 9.9 & 601 & 1 & 1.9622 & 1.9624 \\
\hline 46.945 & 9.3 & 513 & 3 & 1.9339 & 1.9338 \\
\hline 47.274 & 3.9 & 107 & 7 & 1.9212 & 1.9217 \\
\hline 47.819 & 9.3 & 33 & 4 & 1.9005 & 1.9006 \\
\hline 48.380 & 7.0 & 432 & 2 & 1.8798 & 1.8802 \\
\hline 49.650 & 2.2 & 522 & 2 & 1.8347 & 1.8349 \\
\hline 50.368 & 3.1 & 514 & 4 & 1.8102 & 1.8105 \\
\hline 53.314 & 3.6 & 440 & 0 & 1.7169 & 1.7174 \\
\hline 57.417 & 2.4 & 622 & 2 & 1.6036 & 1.6037 \\
\hline 60.853 & 2.9 & 53 & 4 & 1.5210 & 1.5211 \\
\hline 62.631 & 1.8 & 436 & 6 & 1.4820 & 1.4823 \\
\hline 64.575 & 2.5 & 535 & 5 & 1.4420 & 1.4424 \\
\hline 66.037 & 5.0 & 803 & 3 & 1.4136 & 1.4135 \\
\hline 67.571 & 3.1 & 229 & 9 & 1.3852 & 1.3858 \\
\hline 68.192 & 2.4 & 550 & 0 & 1.3741 & 1.3739 \\
\hline 68.767 & 2.5 & 812 & 2 & 1.3640 & 1.3644 \\
\hline 70.668 & 6.0 & $\begin{array}{lll}73 & 1\end{array}$ & 1 & 1.3319 & 1.3323 \\
\hline 71.803 & 6.9 & 732 & 2 & 1.3136 & 1.3136 \\
\hline 73.185 & 3.6 & $\begin{array}{lll}82 & 1\end{array}$ & 1 & 1.2922 & 1.2924 \\
\hline 73.402 & 3.4 & 814 & 4 & 1.2889 & 1.2891 \\
\hline 74.389 & 3.5 & 554 & 4 & 1.2742 & 1.2742 \\
\hline 79.611 & 1.9 & 609 & 9 & 1.2032 & 1.2037 \\
\hline 82.206 & 2.1 & 654 & 4 & 1.1717 & 1.1713 \\
\hline 86.582 & 2.8 & 1004 & 4 & 1.1233 & 1.1233 \\
\hline 91.658 & 1.7 & 549 & 9 & 1.0739 & 1.0741 \\
\hline
\end{tabular}

the desired stoichiometry is difficult to adjust because of vaporization losses inevitably found in normal pressure experiments. This problem can be overcome, however, by synthesis in a closed high pressure system. The intermetallic compound studied in the present work is almost certainly not a real high pressure phase. The function of the applied pressure, however, is merely to keep the reactants together and to allow in this way for the application of rather high temperature which are needed for crystal growth.

Although higher temperature is beneficial to the mixing of starting materials under high pressure, it is found that it is not advantageous to the formation of perfect single crystals in the process of synthesis of zinc-rich intermetallic compounds. It is found that within the temperature range of formation of a certain crystal, the lower the temperature, the more perfect the crystal. It can be explained as follows. The atoms in a crystal are in the state of thermal vibration. The kinetic energy of vibration of particles with a mass $m$ is equal to $p^{2} / 2 m$, where $p$ is the momentum. If this energy exceeds $U(r)$, which is the potential energy of interaction between atoms, the bonding forces will be overcome. Thus the condition for the existence of a condensed system, a crystal in particular, can be written as

$p^{2} / 2 m<U(r)$

Above condition also holds for a liquid. But in the transition from a crystal to a liquid the nature of the order of the atoms changes sharply, because with increasing momenta the average interatomic distances also increase, and the atoms are found more and more often far from the mininum of the $U(r)$. In a liquid, some preferred mutual configurations of atoms are formed statistically, but they are destroyed all the time by thermal motion; ordering is lower the higher is the temperature. At $0 \mathrm{~K}$ when only zero vibrations of the atoms exist, all the phase are crystalline, with the exception of helium, a most quamtum liquid. It is obvious that in a solid the amplitude of vibrations of the atoms is less than the interatomic distance, otherwise they would dominate over the processes of free redistribution - atom migration - which are characteristic of the liquid state, but which may also exist in crystals as fluctuations. The route for the synthesis of intermetallic compounds mentioned above have several advantages over other methods. Firstly, it is more easy to obtain the expected products. Secondly, the synthesis of Sc- $\mathrm{Zn}$ iniermetallic compounds can be carried out in a shorter time. It would last at least 24 hours under normal conditions[3]. In the presence of an external pressure, phase states shift towards condensation and crystallization, and substances whose atomic interaction is described by $U(r)$ without a mininum may crystallize. The effect of the pressure is similar to an increase in attraction forces and opposite to the temperature effect.

\section{References}

[1] G. Bruzzone, M.L.Forasini \& F.Morlo, J. Less-Common Metals, 22, 253(1970).

[2] X.Liu, J. Breu, F. Rau, K. -J. Range, J. Alloys Comp., 243, L5(1996).

[3]T.Siegrist \& Y.Le.Page, J. Less-Common Metals, 127, 189(1987). 